\title{
Environmental regulation, Industrial structure upgrading and Economic growth in Beijing Tianjin Hebei region
}

\author{
Menglu $\mathrm{Li}^{1}$ \\ ${ }^{1}$ School of economics and management \\ Beijing Jiaotong University \\ Beijng, China
}

\begin{abstract}
This paper selects the panel data of 13 cities in Beijing Tianjin Hebei region from 2008 to 2016, and uses the fixed effect model to study the relationship between environmental regulation, industrial structure upgrading and economic growth in Beijing Tianjin Hebei region. The results show that: strengthening environmental regulation can promote the upgrading of industrial structure in Beijing Tianjin Hebei region by reducing the emission of pollutants; the upgrading of industrial structure is conducive to promoting the economic development of Beijing Tianjin Hebei region.
\end{abstract}

\section{INTRODUCTION}

In 2018, famous scholars Nordhaus and Romer made great contributions to innovation, climate and economic growth for the first time, and were awarded the Nobel Prize in economics, which once again aroused the attention of the academic community for economic growth. Since the reform and opening up, China's economy has grown rapidly and made great progress. However, the extensive mode of production has brought serious environmental problems. Data show that the GDP of Beijing, Tianjin and Hebei has increased from 593.342 billion yuan in 1980 to 8458.08 billion yuan in 2019, an increase of 14 times than before ${ }^{(1)}$. However, with the rapid development of economy, serious environmental problems have arisen in Beijing Tianjin Hebei region due to energy consumption mode and economic growth mode. According to the "bulletin on the state of China's ecological environment" in 2018, among the 169 key monitoring cities in Beijing, Tianjin and Hebei, five prefecture level cities in Hebei Province still rank in the bottom 20. At the same time, according to the data, it can be found that there are serious overcapacity problems in the traditional high energy consumption industries in Beijing Tianjin Hebei region. These show that the rapid economic growth of Beijing Tianjin Hebei region is based on high energy consumption and high pollution. In recent years, the strength of environmental regulation in Beijing, Tianjin and Hebei has been continuously strengthened, but we must consider whether these environmental governance measures can accurately promote the industrial structure upgrading of Beijing Tianjin Hebei region with the increasing intensity of environmental regulation? At the same time, can the upgrading of industrial structure really drive the high-quality economic growth of Beijing Tianjin Hebei region? Based on this, this paper begins the research and empirical analysis of these problems.

\section{LITERATURE REVIEW AND HYPOTHESIS}

\section{A. The Impact of Environmental Regulation on Industrial Upgrading}

Mao Jianhui and Guan Chao [1], Zhang Zhongjie [2], Yang Qian, Qin Wenjin and Liu Huajun [3] analyzed the provincial panel data of China, and concluded that environmental regulation is an important factor affecting the upgrading of industrial structure. Yin Yufei and Yang Xuefeng [4], Wan Guangcai, Tao Yunkai and ye Longsheng [5] analyzed the panel data of prefecture level cities in China, and concluded that environmental regulation can directly promote the upgrading of China's industrial structure. Ma Jun and Wang gaiqin [6] analyzed the dynamic panel data of 33 coastal cities in China using the generalized moment estimation (GMM) method. The study found that there was a "U" type relationship between environmental regulation and industrial structure upgrading in China's coastal areas, which was affected by the inflection point. Gao Ming and Chen qiaohui [7] analyzed the heterogeneity of environmental regulation between the eastern and western regions, and the results showed that voluntary environmental regulation in the eastern region did not form an effective incentive for industrial upgrading. In the central and western regions, only the mandatory environmental regulation has promoted the industrial upgrading obviously. Therefore, this paper puts forward hypothesis 1: environmental regulation helps to upgrade industrial structure. 


\section{B. The Impact of Industrial Utructure upgrading on Economic Growth}

There are two main views on the upgrading of industrial structure and economic growth. Some scholars believe that the upgrading of industrial structure will unilaterally affect economic growth. Xuan Chen and Weiwen Qian [8], Zhu Fenghui and Liu Lifeng [9] analyzed the panel data of prefecture level cities in China, and the results showed that the upgrading of industrial structure promoted the high-quality economic development. Zhang Haijun and Zhang Zhiming [10] conducted an empirical study based on the Yangtze River Delta urban agglomeration. The results show that promoting the advanced and rational development of industrial structure is conducive to promoting regional economic growth. Zhou Yixin and Guo Zhen [11] through the study of Northeast China's old industrial base, through empirical research, it is concluded that the structural changes of all industries in Northeast China have a positive impact on regional economic development. Yan Du and Qian Wu [12] found that industrial structure change has threshold effect on economic growth, and the time node of threshold effect is about 2009-2010.

Another kind of scholars think that the upgrading of industrial structure and economic growth are mutually affected. Song Baolin, Bai Shijie and Guo Yuan [13], Tian Yinhua and Kuang Chang'e [14] established a panel vector autoregressive model and used the impulse response function method to study the dynamic interaction between them. The study found that economic growth can promote the upgrading of industrial structure. Zhang Yongheng and Xue Jinli [15] analyzed the relationship between three types of industrial structure and economic growth by using vector autoregressive model. It is found that various types of industrial structure and economic growth have a stable and mutually promoting relationship. Du Jun, Kou Jiali and Zhao Peiyang [16] also studied the dynamic relationship between marine industrial structure upgrading and economic growth by using vector autoregressive model. It is found that the upgrading of marine industrial structure has a significant impact on marine economic growth. In the short term, the positive effect of marine economic growth on the upgrading of marine industrial structure is not obvious. In the long run, marine economic growth can promote the optimization of marine industrial structure. Through the above review, this paper puts forward hypothesis 2: industrial upgrading helps economic growth.

From the above-mentioned scholars' research, we can find that most scholars only simply analyzed the relationship between environmental regulation, industrial structure upgrading and economic growth in the past. Due to the special status of Beijing Tianjin Hebei region, exploring its environmental regulation, industrial structure upgrading and regional growth will provide a theoretical basis for the study of other regions, so as to drive the economic development of the whole China.

\section{MODEL SETTING, VARIABLE SELECTION, DATA SOURCE AND PROCESSING}

\section{A. Model Setting}

This paper mainly studies the relationship between environmental regulation and industrial structure upgrading, industrial structure upgrading and regional economic growth. According to the above analysis and hypothesis, this paper selects the panel data of 13 cities in Beijing Tianjin Hebei region from 2008 to 2016, and constructs the basic panel regression model and the panel regression model with lag effect by referring to the research model of Wan Guangcai,Tao Yunkai and ye Longsheng [5] Model.

Model 1: the impact of environmental regulation on the upgrading of industrial structure

$$
\mathrm{CYi}_{\mathrm{it}}=\alpha_{0}+\alpha_{1} \mathrm{ER}_{\mathrm{it}}+\alpha_{2} \mathrm{KFi}_{\mathrm{it}}+\alpha_{3} \mathrm{FDI}_{\mathrm{it}}+\varepsilon_{\mathrm{it}}
$$

Model 2: the impact of industrial structure upgrading on economic growth

$$
\mathrm{LGDP}_{\mathrm{it}}=\alpha_{0}+\alpha_{1} \mathrm{CY}_{\mathrm{it}}+\alpha_{2} \mathrm{LK}_{\mathrm{it}}+\alpha_{3} \mathrm{Ll}_{\mathrm{it}}+\varepsilon_{\mathrm{it}}
$$

\section{B. $\quad$ Variable Selection}

a) The variable is economic growth (LGDP $\left.P_{i t}\right)$ : Zhang Shuhong, Yang Wancai and $\mathrm{Wu}$ Xinqian [17] pointed out that economic growth takes into account the size of the total economic volume, so it is an important economic indicator that can objectively reflect the level of a country or region. This paper uses regional per capita GDP to measure regional economic growth.

b) Industrial structure upgrading $\left(C Y_{i t}\right)$ : There are many measurement indicators related to industrial upgrading. Usually, the change of relative scale of different industries is used to analyze the upgrading of industrial structure, such as the proportion of the secondary and tertiary industries in GDP, but the above indicators ignore the impact of the primary industry. Therefore, this paper uses the formula $C Y=\sum_{i=1}^{3} l_{i} i=l_{1} \times 1+t_{2} \times 2+t_{3} \times 3$ for reference from Wan Guangcai,Tao Yunkai and ye Longsheng [5]. In this formula, li refers to the proportion of the $i$ industry in the GDP of the region. It can be seen that the value of CY is between 1 and 3 . The closer the result is to 1 , the lower the level of industrial structure is, and the closer the result is to 3 , the higher the level of industrial structure is.

c) Environmental regulation $\left(E R_{i t}\right)$ : There is no uniform standard for the study of environmental governance at home and abroad, and there are great differences. In this paper, the industrial output value, $\mathrm{SO}_{2}$ and wastewater data of 13 cities in Beijing Tianjin Hebei region are used to construct the environmental regulation index. Referring to javorick and Shang Jin [18], the following formula is constructed. That is: $\mathrm{ER}_{\mathrm{it}}=(2 * \mathrm{t}$ year $\mathrm{i}$ actual total industrial output value) / (Industrial $\mathrm{SO}_{2}$ emission in $\mathrm{i}$ area in $\mathrm{t}$ year + industrial wastewater discharge in i area in t year).

d) Other control variables: The degree of economic openness $\left(\mathrm{KF}_{\mathrm{it}}\right)$, that is, international trade between different countries, is expressed by the proportion of total 
import and export to GDP; Foreign direct investment $\left(\mathrm{FDI}_{\mathrm{it}}\right)$, which is expressed by the proportion of actual use of foreign capital and GDP; Fixed asset investment $\left(\mathrm{LK}_{\mathrm{it}}\right)$ The increase of fixed assets will increase the production capacity and stimulate the production demand, which will eventually bring economic development. This paper uses the fixed assets investment in that year (excluding farmers); The number of labor force $\left(\mathrm{Ll}_{\mathrm{it}}\right)$, and human capital has an important impact on the economy. This paper selects the number of employees at the end of the year of each city in Beijing Tianjin Hebei region to measure. The descriptive statistics of each variable are shown in Table 1. follows.

TABLE I. DESCRIPTIVE STATISTICS OF REGIONAL VARIABLES IN SAMPLE

\begin{tabular}{|c|c|c|c|c|c|c|}
\hline Variable & Variable meaning & $\begin{array}{c}\text { Observ } \\
\text { ations }\end{array}$ & $\begin{array}{l}\text { Mean } \\
\text { value }\end{array}$ & $\begin{array}{l}\text { Standard } \\
\text { deviation }\end{array}$ & Minimum & Maximum \\
\hline GDPit & Economic growth & 117 & 17.0697 & 0.9281 & 15.6621 & 19.3634 \\
\hline CYit & $\begin{array}{c}\text { Upgrading of } \\
\text { industrial structure }\end{array}$ & 117 & 2.2963 & 0.1615 & 2.0983 & 2.7972 \\
\hline ERit & $\begin{array}{c}\text { Environmental } \\
\text { regulation }\end{array}$ & 117 & 1.1580 & 0.9701 & 0.1396 & 4.2478 \\
\hline KFit & Economic Openness & 117 & 0.2802 & 03948 & 0.0065 & 1.9320 \\
\hline $\mathrm{FDI}_{\mathrm{it}}$ & $\begin{array}{l}\text { Foreign direct } \\
\text { investment }\end{array}$ & 117 & 0.0229 & 0.2161 & 0.0007 & 0.1206 \\
\hline $\mathrm{K}_{\mathrm{it}}$ & $\begin{array}{c}\text { Investment in fixed } \\
\text { assets }\end{array}$ & 117 & 16.7311 & 0.8966 & 14.6954 & 19.1267 \\
\hline $\mathrm{L}_{\mathrm{it}}$ & $\begin{array}{l}\text { Number of labor } \\
\text { force }\end{array}$ & 117 & 13.96 & 0.9127 & 12.7932 & 16.6657 \\
\hline
\end{tabular}

\section{Data source and processing}

This paper selects the panel data of 13 cities in Beijing Tianjin Hebei region from 2008 to 2017, and the data are derived from China's urban statistical yearbook and economic yearbooks of various provinces over the years. At the same time, economic growth (LGDP $\left.{ }_{i t}\right)$, fixed asset investment $\left(\mathrm{LK}_{\mathrm{it}}\right)$ and labor force $\left(\mathrm{Ll}_{\mathrm{it}}\right)$ are all in logarithmic form, eliminating the influence of heteroscedasticity on the results.

\section{RESULTS AND ANALYSIS}

\section{A. Baseline Regression Results}

In this paper, Eviews 9.0 is used to test the regression results of the above equations (1) and (2). The p value is 0 , and the mixed effect is excluded. After that, Hausman test was carried out for the results, and the $p$ value was 0 , which excluded the random effect. Therefore, the fixed effect is more suitable for this study. In this paper, the specific results of the above regression are arranged in Table 2.

According to the result of formula (1), the coefficient in front of environmental regulation $\left(\mathrm{ER}_{\mathrm{it}}\right)$ is significantly positive, which means that the increase of environmental regulation intensity will produce the effect of "survival of the fittest", which can promote the upgrading of industrial structure. The hypothesis 1 of this paper is verified. The results show that the effect of economic openness $\left(\mathrm{KF}_{\text {it }}\right)$ on the upgrading of industrial structure is not obvious in Beijing Tianjin Hebei region. The coefficient of foreign direct investment $\left(\mathrm{FDI}_{\mathrm{it}}\right)$ is significantly negative, which indicates that the foreign investment introduced by Beijing Tianjin Hebei region hinders the upgrading of industrial structure, and indicates that Beijing Tianjin Hebei region needs to introduce foreign investment which is conducive to the upgrading of industrial structure.

According to the regression result of formula (2), the coefficient before the upgrading of industrial structure $\left(\left(\mathrm{CY}_{\mathrm{it}}\right)\right)$ is significantly positive, which indicates that the optimization of industrial structure will promote economic growth. We can find that the change of industrial structure will affect the mismatch of social resources. The essence of industrial structure optimization is the transformation of high efficiency production industry. The control variable fixed asset investment $\left(\left(\mathrm{LK}_{\mathrm{it}}\right)\right)$ has not passed the significance test, which shows that the effect of fixed asset investment on economic growth in Beijing Tianjin Hebei region is not obvious. The human capital $\left(\left(\mathrm{Ll}_{\mathrm{it}}\right)\right)$ is significantly negative, which indicates that the increase of the number of people alone can not guarantee the economic growth, and it is necessary to pay attention to the introduction of high-quality talents.

TABLE II. BASELINE REGRESSION RESULTS

\begin{tabular}{|c|c|c|}
\hline \multirow{2}{*}{ Variable } & \multicolumn{2}{|c|}{ Fixed effect } \\
\cline { 2 - 3 } & $\mathrm{CY}_{\mathrm{it}}$ & $\mathrm{LGDP}_{\mathrm{it}}$ \\
\hline $\mathrm{ER}_{\mathrm{it}}$ & $0.01628^{*}$ & \\
& $(1.5594)$ & \\
\hline $\mathrm{KF}_{\mathrm{it}}$ & -0.0135 & \\
& $(-0.5938)$ & \\
\hline $\mathrm{FDI}_{\mathrm{it}}$ & $-1.1839^{*}$ & $0.9222^{* * *}$ \\
& $(-1.7882)$ & $(5.3818)$ \\
\hline $\mathrm{CY}_{\mathrm{it}}$ & & -0.0108 \\
& & $(-0.4938)$ \\
\hline $\mathrm{LK}_{\mathrm{it}}$ & & $-0.0656^{*}$ \\
& & $(-1.8194)$ \\
\hline $\mathrm{Ll}_{\mathrm{it}}$ & & \\
& & \\
\hline
\end{tabular}

a. ***Indicates that it is significant at the $1 \%$ level, ** indicates that it is significant at the $5 \%$ level, and * indicates that it is significant at the $10 \%$ level. In brackets are $t$ statistics. The following tables are the same.

\section{B. Robustness Check}

In the fixed effect model, the regression results are shown in Table 3. The series (1) and (2) represent the regression results of the benchmark model with one lag period. According to the results, we can see that the core explanatory variables are significant, which indicates that the promotion of environmental regulation on the upgrading of industrial structure is obvious, and the upgrading of industrial structure will also promote economic growth. At the same time, through the 
regression results, we found that both the core explanatory variables and the control variables, except for the significant changes of individual variables, their coefficient symbols are basically consistent with table 2 . Therefore, it can be considered that the empirical test conclusion of this paper is robust and reliable.

TABLE III. TABLE TyPe STYLES

\begin{tabular}{|c|c|c|}
\hline \multirow{2}{*}{ Variable } & \multicolumn{2}{|c|}{ Fixed effect } \\
\cline { 2 - 3 } & $\mathrm{CY}_{\mathrm{it}}$ & $\mathrm{LGDP}_{\mathrm{it}}$ \\
\hline $\mathrm{ER}_{\mathrm{i}(\mathrm{t}-1)}$ & $0.0176^{*}$ & \\
\hline $\mathrm{CY}_{\mathrm{i}(\mathrm{t}-\mathrm{l})}$ & $(1.8039)$ & \\
\hline & & $1.2953^{* * *}$ \\
& & $(4.6039)$ \\
\hline
\end{tabular}

a. Limited to space, this table reports only the regression results of core explanatory variables.

\section{CONCLUSION AND SUGGESTIONS}

Environmental protection and economic growth are the eternal topics of human concern. This paper uses the municipal panel data of Beijing, Tianjin and Hebei to construct an econometric model to analyze the relationship among environmental regulation, industrial structure upgrading and economic growth.

From the perspective of the overall economy of Beijing Tianjin Hebei region, increasing environmental regulation does not hinder the economic development of Beijing Tianjin Hebei region. It will affect the optimization of the overall industrial structure through foreign direct investment, but we need to pay attention to the introduction of high-quality investment, which shows that strengthening environmental regulation and reducing pollutant emissions will help to improve the industrial structure of Beijing Tianjin Hebei region, and ultimately make Beijing Tianjin Hebei region To a certain extent, the economy of the district has increased slightly.

The above conclusions have important implications:

We should improve the environmental protection laws and regulations in Beijing Tianjin Hebei region and improve the legal system of environmental protection. Environmental regulation can not be separated from legal means. Different management policies should be implemented according to local conditions in different regions. At the same time, the government should constantly revise the existing environmental regulation laws and bring the problems encountered in the process of environmental regulation into law in time. For example, we can appropriately increase the management of emissions trading, so as to internalize the environmental losses caused by enterprises.

The government should speed up the upgrading of industrial structure, optimize the allocation of resources and reduce the use of high energy consumption energy in Beijing Tianjin Hebei region. In order to improve the energy use structure of Beijing Tianjin Hebei region, the government should encourage the R \& D and upgrading of new energy industry.

Enterprises should carry out technological innovation to reduce the emission of pollutants. Enterprises should make full use of the scientific research and education resources in Beijing, Tianjin and Hebei, increase the training and introduction of innovative talents, pay attention to the transformation of scientific and technological results, and finally achieve product upgrading, comprehensive utilization of resources and pollutant emission standards.

\section{ACKNOWLEDGMENT}

First of all, I am very grateful for the recognition of my family. During the epidemic at home, I have a good environment for writing papers. Secondly, I thank my tutor for providing me with ideas and help. In addition, I thank my classmates and friends around me for helping me overcome the difficulties in writing papers. I would like to express my most sincere thanks to you.

\section{REFERENCES}

[1] Mao Jianhui, Guan Chao. Does environmental regulation restrain the upgrading of industrial structure? -- an analysis of nonlinear threshold model based on government behavior [J]. Finance and trade research, 2020, 31 (3): 29-42.

[2] Zhang Zhongjie. The impact of environmental regulation on the upgrading of industrial structure: an analysis based on the mediating effect $[\mathrm{J}]$. Statistics and decision making, 2019, 35 (22): 142-145.

[3] Yang Qian, Qin Wenjin, Liu Huajun. Does environmental regulation promote the optimization and upgrading of industrial structure? [J]. Shanghai Economic Research, 2019 (6): 83-95.

[4] Yin Yufei, Yang Xuefeng. Environmental regulation, technological innovation and urban industrial structure upgrading: Based on the data of 113 cities [J]. Jianghan forum, 2020 (4): 4855 .

[5] Wan Guangcai, Tao Yunkai, ye Longsheng. Environmental regulation, industrial transformation and high quality economic development in Anhui [J]. East China economic management, 2019,33 (11): 24-29.

[6] Ma Jun, Wang gaiqin. Impact of environmental regulation on industrial structure upgrading: An Empirical Analysis Based on generalized moment estimation of China's coastal city system [J]. Science and technology management research, 2019, 39 (9): 163169.

[7] Gao Ming, Chen qiaohui. The impact of different types of environmental regulations on industrial upgrading [J]. Industrial technology economy, 2019,38 (1): 91-99.

[8] Xuan Chen,Weiwen Qian. Effect of marine environmental regulation on the industrial structure adjustment of manufacturing industry: An empirical analysis of China's eleven coastal provinces[J]. Elsevier Ltd,2020,113.

[9] Zhu Fenghui, Liu Lifeng. Upgrading of industrial structure and high quality economic development in China: Based on empirical data of cities at prefecture level and above $[\mathrm{J}]$. Journal of Yunnan University of Finance and economics, 2020,36 (6): 42-53.

[10] Zhang Haijun, Zhang Zhiming. Financial opening, industrial structure upgrading and economic integration development: An Empirical Study Based on the Yangtze River Delta urban agglomeration [J]. Economic issues exploration, 2020 (5): 122133.

[11] Zhou Yixin, Guo Zhen. Multiplier effect of industrial structure upgrading on economic development in Northeast China [J]. Statistics and decision making, 2019,35 (23): 139-143.

[12] Yan Du, Qian Wu. Threshold Effect of Industrial Structure Change on Economic Growth[J]. International Journal of Business and Economics Research,2019,8(3).

[13] Song Baolin, Bai Shijie, Guo Yuan. Empirical analysis on the relationship between economic growth, energy consumption and industrial structure upgrading [J]. Statistics and decision making, 2018,34 (20): 142-144.

[14] Tian Yinhua, Kuang Chang'e. Empirical Study on the relationship between industrial structure upgrading and economic growth in Hunan Province -- Based on the data from 1978 to $2012[\mathrm{~J}]$. 
Journal of Xiangtan University (PHILOSOPHY AND SOCIAL SCIENCES), 2014,38 (6): 50-53 + 58.

[15] Zhang Yongheng, Xue Jinli. Dynamic relationship between industrial transformation and upgrading and economic growth [J]. Statistics and decision making, 2020,36 (6): 96-99.

[16] Du Jun, Kou Jiali, Zhao Peiyang. Upgrading of marine industrial structure, marine scientific and technological innovation and marine economic growth: an analysis based on the provincial data panel vector autoregressive (pvar) model [J]. Science and technology management research, 2019, 39 (21): 137-146.

[17] Zhang Shuhong, Yang Wancai, Wu Xinqian. Prediction of per capita GDP of Henan Province during the 12th Five Year Plan period [J]. Mathematical statistics and management, 2014,33 (3): 394-399.

[18] Beata Smarzynska Javorcik, Shang-Jin Wei. Pollution Havens and Foreign Direct Investment: Dirty Secret or Popular Myth? [J]. Walter de Gruyter,2011,3(2). 